\title{
The Effect of Propanone Molecule on Supramolecular Arrangement of Solvatomorphs of a Novel Anticancer Sulfonamide Chalcone
}

Jean Marcos F. Custodio, Wesley F. Vaz, Mirian Rita C. de Castro, Caridad N. Perez and Hamilton B. Napolitano Universidade Estadual de Goiás

Sulfonamide chalcones are hybrid compounds formed by sulfonamide and chalcone moieties, with various biological activities ${ }^{1-3}$. A new sulfonamide chalcone $\mathrm{C}_{24} \mathrm{H}_{20} \mathrm{CL}_{2} \mathrm{~N}_{2} \mathrm{O}_{6} \mathrm{~S}$ was synthesized and its biological tests indicate activities against prostate and colon cancer tumor cells [PC-3 = 97.51 \pm 0.65 and HCT$116=100.00 \pm 1.83$ ]. Two single crystals of solvatomorphs (SFV-SV and SFC) were obtained by different crystallization experiments and were collected on Bruker APEX II CCD diffractometer. Both structures crystallized in the centrosymmetric P-1 space group and were refined by SHELXL $\left[\mathrm{R}_{1}=0.0597\right.$ and $\mathrm{S}=1.023$ for SFC-SV; $\mathrm{R}_{1}=0.0695$ and $\left.\mathrm{S}=1.053\right]$. The SFC-SV structure has one propanone molecule in the asymmetric unit and the values of dihedral angles indicate the planarity throughout the chalcone moiety. The SFC structure has two independent molecules in asymmetric unit (SFC- $\alpha$ and SFC- $\beta$ ) and its residual electronic density was refined by SQUEEZE routine by PLATON. Both crystal forms can be obtained by rotations around $\sigma$ bonds and the planarity decreases following the order SFC-SV $>$ SFC- $\beta>$ SFC- $\alpha$. The crystal packing of both molecules are stabilized by interactions of type $\mathrm{C}-\mathrm{H} \cdots \mathrm{O}, \mathrm{N}-\mathrm{H} \cdots \mathrm{O}$ and $\mathrm{C}-\mathrm{H} \cdots \mathrm{Cl}$. In SFC-SV, propanone molecules are responsible for binding two dimmer chains, while in SFC the solvent space is substituted by voids on refinement. The Figure 1 shows the supramolecular arrangements of SFC-SV, with solvent molecules in black, and SFC. In addition, the packing is stabilized by $\mathrm{C}-\mathrm{H} \cdots \pi$ and $\pi \cdots \pi$, as described on the Hirshfeld surface $d_{\text {norm }}$ and Hirshfeld surface shape index.

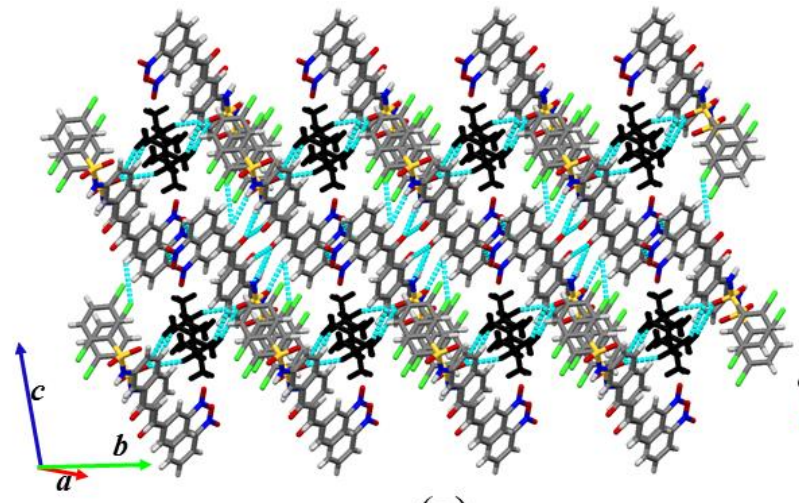

(a)

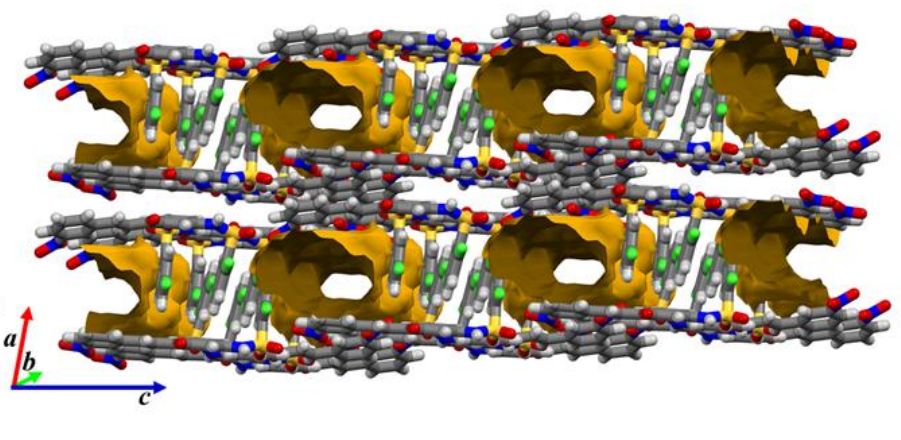

(b)

Figure 1: Supramolecular arrangements of solvatomorphs SFC-SV (a) and SFC (b). Propanone molecules are represented by black color (a) and voids are represented by yellow color (b).

\section{Acknowledgements:}

The authors would like to thank the Brazilian agency Coordenação de Aperfeiçoamento Pessoal de Nível Superior (CAPES) for financial support.

\section{References:}

1 D. Caridha, A. K. Kathcart, D. Jirage and N. C. Waters, Bioorg. Med. Chem. Lett., 2010, 20, 3863-3867.

2 P. Graziela, A. Martins, A. Camila, O. Menegatti, L. D. Chiaradia-delatorre, K. Navakoski, D. Oliveira, R. Victorio, C. Guido, A. De, J. Vernal, R. Augusto, R. José and H. Terenzi, Eur. J. Med. Chem., 2013, 64, 35-41.

3 M. M. Ghorab, F. A. Ragab, H. I. Heiba, M. G. El-Gazzar and S. S. Zahran, Eur. J. Med. Chem., 2015, 92, 682-692. 